\title{
Two hundred fifty years of aerosols and climate: the end of the age of aerosols
}

\author{
S. J. Smith ${ }^{1}$ and T. C. Bond ${ }^{2}$ \\ ${ }^{1}$ Joint Global Change Research Institute, Pacific Northwest National Laboratory, 5825 University Research Court, Suite 3500, \\ College Park, MD 20740, USA \\ ${ }^{2}$ Department of Civil \& Environmental Engineering, University of Illinois, Urbana-Champaign, 205 N. Mathews Ave., \\ Urbana, IL 61801, USA
}

Correspondence to: S. J. Smith (ssmith@pnnl.gov)

Received: 19 February 2013 - Published in Atmos. Chem. Phys. Discuss.: 11 March 2013

Revised: 22 November 2013 - Accepted: 7 December 2013 - Published: 20 January 2014

\begin{abstract}
Carbonaceous and sulfur aerosols have a substantial global and regional influence on climate, resulting in a net cooling to date, in addition to their impact on health and ecosystems. The magnitude of this influence has changed substantially over the past and is expected to continue to change into the future. An integrated picture of the changing climatic influence of black carbon, organic carbon and sulfate over the period 1850 through 2100 , focusing on uncertainty, is presented using updated historical inventories and a coordinated set of emission projections. We describe, in detail, the aerosol emissions from the RCP4.5 scenario and its associated reference scenario. While aerosols have had a substantial impact on climate over the past century, we show that, by the end of the 21 st century, aerosols will likely be only a minor contributor to radiative forcing due to increases in greenhouse gas forcing and a net global decrease in pollutant emissions. This outcome is even more certain under a successful implementation of a policy to limit greenhouse gas emissions as low-carbon energy technologies that do not emit appreciable aerosol or $\mathrm{SO}_{2}$ are deployed.
\end{abstract}

\section{Introduction}

Human activities, particularly fuel combustion and land-use changes, have altered the composition of the atmosphere, resulting in changes in tropospheric and stratospheric ozone levels, aerosol loadings, and greenhouse gas (GHG) concentrations. Radiative forcing of climate has been impacted in numerous ways by these changes, most notably through increasing greenhouse gas concentrations and emissions of aerosols and their precursors.

Observational and modeling studies have concluded that the net radiative forcing from aerosols is negative, resulting in a net cooling impact. This negative forcing has "masked" some of the positive forcing from greenhouse gases (Wigley, 1989; Charlson et al., 1991; Kiehl and Briegleb, 1993; Taylor and Penner, 1994). As found by historical pattern-matching studies (Santer et al., 1995), this aerosol influence is critical to explaining the historical spatial and temporal patterns of temperature change. The complex behavior of aerosols in the atmosphere, particularly with respect to clouds, gives rise to substantial uncertainty in aerosol forcing. While coupled atmosphere-chemistry models can, in principle, consistently estimate forcing from all components, these estimates vary widely (Kiehl, 2007; Schulz et al., 2006). In addition, not all models include all forcing components, and the emission-toforcing relationships as embodied in these models may not cover the entire range of potential forcing.

We aim in this work to examine the net influence of aerosols on climate over the period 1850 through 2100, focusing on how uncertainty in current aerosol forcing impacts trends and the relative importance of aerosol forcing to that from greenhouse gases over time.

Aerosol species considered in this paper include the major components of submicron particles: sulfate, black carbon (BC), and organic carbon (OC). Of these species, black carbon has positive direct forcing, and sulfate and organic carbon exert negative forcing. Additional species and interactions also play a role, as will be discussed below. 
Section 2 below discusses the historical emissions used in this analysis, followed by a discussion of the future emission scenarios in Sect. 3, with a particular focus on carbonaceous aerosol emissions. The methodology for estimating aerosol forcing is discussed in Sect. 4. Radiative forcing from aerosols is then assessed for a $250 \mathrm{yr}$ period using a set of simple relationships between emissions and aerosol forcing that allow a wide range of bounding cases to be considered. The paper concludes with a discussion.

\section{Historical emissions}

Historical emissions of anthropogenic sulfur dioxide for 1850-2005 are taken from Smith et al. (2011). This estimate of global emissions has annual resolution and considers all sources. Black and organic carbon emissions for each decadal year from 1850 to 2000 are from Bond et al. (2007) as updated in Lamarque et al. (2010). Values for $5 \mathrm{yr}$ intervals were interpolated using trends from Bond et al. (2007). Historical estimates of $\mathrm{BC}, \mathrm{OC}$, and $\mathrm{SO}_{2}$ emissions from open biomass burning (Van der Werf et al., 2006; Schultz et al., 2008; Mieville et al., 2010) and agricultural waste burning are described in Lamarque et al. (2010) and Smith et al. (2011).

While anthropogenic $\mathrm{SO}_{2}$ emissions in 1850 are small ( $2 \%$ of year 2000 emissions), BC and OC emissions are more significant, $20 \%$ and $40 \%$ of year 2000 emissions in the inventory used here. Year 1850 anthropogenic BC and $\mathrm{OC}$ emissions are largely emissions from biomass used in the residential sector for heating and cooking (Bond et al., 2007). Building biomass consumption is estimated using per-capita consumption assumptions (Fernandes et al., 2007). Both biomass consumption and emissions factors at this point in the past are uncertain; although there is more confidence in the trends from 1850 to 1900 than the absolute magnitudes.

Starting in 1850 , global emissions show a general increase through the industrial period, driven in large part by fuel combustion in industry and power plants for $\mathrm{SO}_{2}$ and coal and biomass consumption in the residential sector for $\mathrm{BC}$ (Fig. 1). There was a particularly rapid increase in $\mathrm{SO}_{2}$ emissions from 1950 through 1970, driven largely by emissions from electric power plants. Global $\mathrm{SO}_{2}$ emissions peaked in the 1970s as emission controls began to be widely deployed and have generally declined since. Although emissions increased slightly from 2000 to 2005, they have subsequently declined (Klimont et al., 2013).

The 20th-century increases in BC emissions started a bit later, driven by increased emissions from the transportation and industrial sectors and increased forest fire emissions. Unlike sulfur dioxide, global anthropogenic black carbon emissions do not appear to have peaked as of the latest inventory estimate for 2000. Anthropogenic black carbon emis-
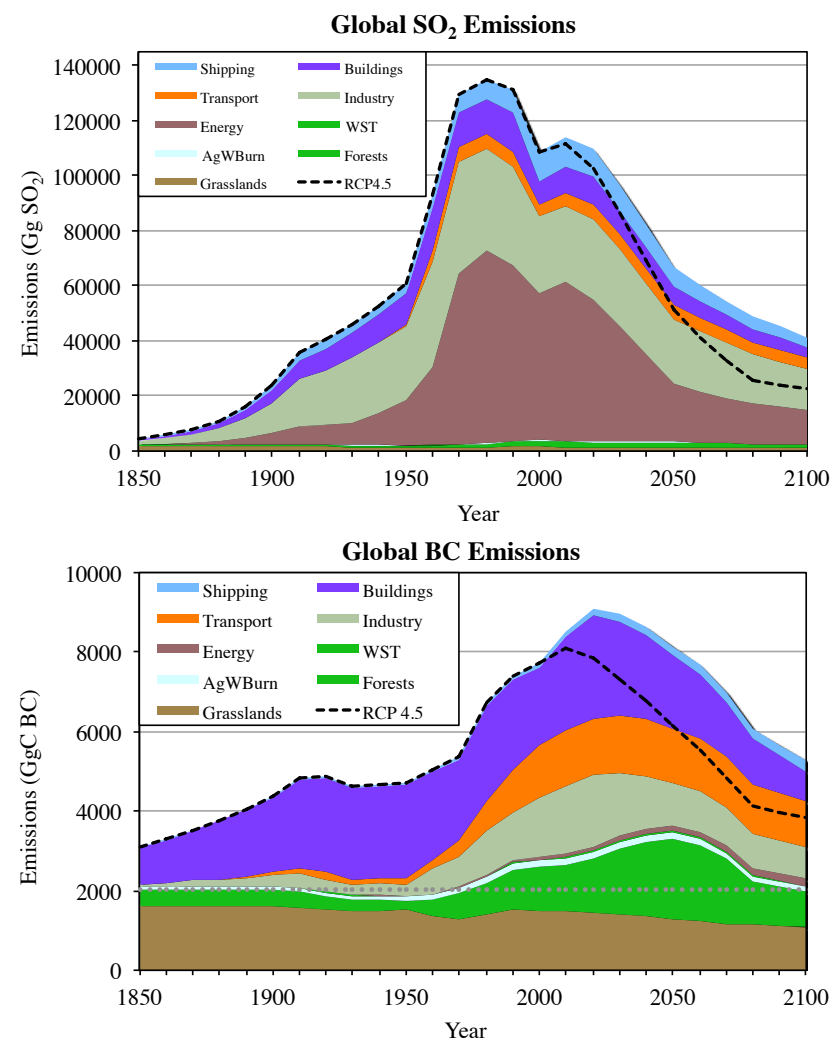

Fig. 1. Top: historical and future sulfur dioxide emissions. Future emissions under the GCAM reference (no climate policy) scenario are shown in the shaded region. Total emissions under the RCP4.5 climate policy scenario are shown in the black dashed line. Bottom: historical and future black carbon emissions under the GCAM reference and climate policy scenarios. The grey dotted line shows the assumed preindustrial BC open burning emissions (see text). Note that the building sector includes residential and commercial buildings (see ESM for sector definitions).

sions were also significant even in 1850 , due to the use of biomass and coal for residential cooking and heating.

OC emissions are dominated by open burning (forests and grasslands) and the buildings sector (Figs. S2 and S5) and increased over the latter half of the 20th century, largely due to increased deforestation.

Global sulfur emissions are relatively well known, with global uncertainty estimated to be in the range of $8-14 \%$ over the 20th century (Smith et al., 2011). Uncertainty in black carbon emissions is much larger, with an estimated range in 1996 of $+150 \%$ to $-30 \%$ (Bond et al., 2004).

\section{Future emissions}

\subsection{Future emission scenarios}

The scenarios used here were developed using the Global Change Assessment Model (GCAM) as part of the 
Representative Concentration Pathways (RCP) processes, which provided scenarios to be used for climate research, including international model intercomparison exercises (Moss et al., 2010). We use two scenarios, a "reference" and a "climate-policy" scenario, described in Thomson et al. (2011).

The GCAM reference scenario is a self-consistent pathway of long-term global and regional developments in the energy and agricultural systems, with no specific actions to slow emissions of greenhouse gases (see electronic supplementary material, ESM). Emissions of local air pollutants are simulated within these scenarios in an aggregate manner, with emission controls assumed to increase as incomes increase (Smith and Wigley, 2006). Historical trends indicate that, as incomes increase, concern about traditional air pollutants rises and the ability to reduce them is improved. These effects are implemented in the GCAM at the fuel and sector levels by using emission factors that decrease as a function of income (Smith et al., 2005; Smith, 2005; see ESM). As incomes increase, we assume that the aggregate emission factor within each sector decreases, becoming similar at high-income levels. This decrease represents more stringent pollution control standards over time, given that GCAM does not represent individual pollution control technologies (although different energy supply and demand technologies are represented). This treatment captures expected behavior, consistent with historical evidence given the assumed growth in regional incomes. The representation in GCAM is further discussed in Smith et al. (2011, Sect. S4).

The GCAM emission projections using this approach are broadly similar to those from other long-term models (van Vuuren et al., 2011; Riahi et al., 2011), although there are differences in detail. These results can also differ from the projections of more detailed models that contain more specific technology detail, particularly over shorter timescales of 1-2 decades (e.g., Yan et al., 2011; see below).

The RCP4.5 climate policy scenario begins with all the assumptions in the reference scenario, and adds a carbon price in all sectors such that total radiative forcing in 2100 stabilizes at $4.5 \mathrm{~W} \mathrm{~m}^{-2}$ by 2100 (Thomson et al., 2011). Energy prices increase, which induces both decreases in enduse service demands but also induces shifts to more efficient technologies. The addition of a carbon price induces shifts in technology choices, including a shift in electric generation toward renewable, nuclear, and fossil energy with CCS; and shifts in end-use sectors toward electricity and biomass fuels (Clarke et al., 2007; Thomson et al., 2011). The same emission factors were assumed for the climate policy scenario such that any reduction in fossil fuel use results in a further reduction in pollutant emissions.

In these scenarios, emissions from forest and grassland burning are determined by land use and rates of deforestation. Changes in fire frequency due to changes in climate are not considered. The climate policy scenario also assumes that carbon in terrestrial ecosystems is valued at the same level as carbon emitted by fossil fuel use (Wise et al., 2009), which results in a reversal of deforestation trends in the RCP4.5 scenario to net reforestation over the 21 st century. This results in a net decreases in aerosol emissions from burning associated with deforestation.

\subsection{Future sulfur dioxide emissions}

Global sulfur dioxide emissions (Figs. 1, S2, S3) are similar to those of Smith et al. (2005), using an earlier version of this model. In this new projection, total global emissions begin declining by 2020 as compared to after this point in previous scenarios. Emissions fall to $42 \mathrm{Tg} \mathrm{SO}$ by the end of the century in the reference scenario.

In the case of a successful climate policy implementation, as assumed in the RCP4.5 scenario, most coal use by end of the century shifts to technologies that incorporate carbon capture and geologic storage (CCS), which has inherently low $\mathrm{SO}_{2}$ emissions. Anthropogenic emissions fall to $23 \mathrm{Tg}$ $\mathrm{SO}_{2}$ by 2100 in the RCP4.5 policy scenario, a level not seen since the beginning of the 20th century.

The future trends in these scenarios are dominated by China, currently the largest emitter of sulfur dioxide. In these scenarios, emissions in China peak around 2020 and then fall substantially, replicating the general pattern seen historically in, for example, Western Europe. The GCAM reference scenario appears to be too pessimistic regarding sulfur dioxide emissions controls in China, where emissions appear to have already peaked (Li et al., 2010; Lu et al., 2011). Global $\mathrm{SO}_{2}$ emissions in the RCP4.5 scenario projection for 2010 are close to recent estimates (Klimont et al., 2013). The RCP4.5 scenario may, therefore, present a more realistic picture of near-term climate forcing trends regarding $\mathrm{SO}_{2}$ emissions than the reference scenario.

\subsection{Future carbonaceous aerosol emissions}

Global BC emissions peak in 2035 in the reference case scenario and decline to slightly below current levels by 2050. By 2100, global BC emissions decline to $5300 \mathrm{Gg} \mathrm{yr}^{-1}$, similar to estimated emissions for 1970 .

Over the first half of the 21 st century, continued emissions from the building and industrial sectors and emission increases from deforestation result in a net increase in BC emissions in the reference scenario (Figs. 2, S2, S5). After 2035, emissions decline, due in part to the replacement of building sector biomass and coal with cleaner and more convenient fuels. Emission decreases in Asia and Africa mirror similar decreases historically seen in North America, Europe, and Japan. The second half of the 21 st century also exhibits decreases in emissions from the industrial sector as industrial activities are assumed to move away from smaller, lessefficient operations to more efficient, and generally largerscale, technologies. Emission decreases in the transportation sector occur as more stringent emission controls eventually 
Global Black Carbon Emissions

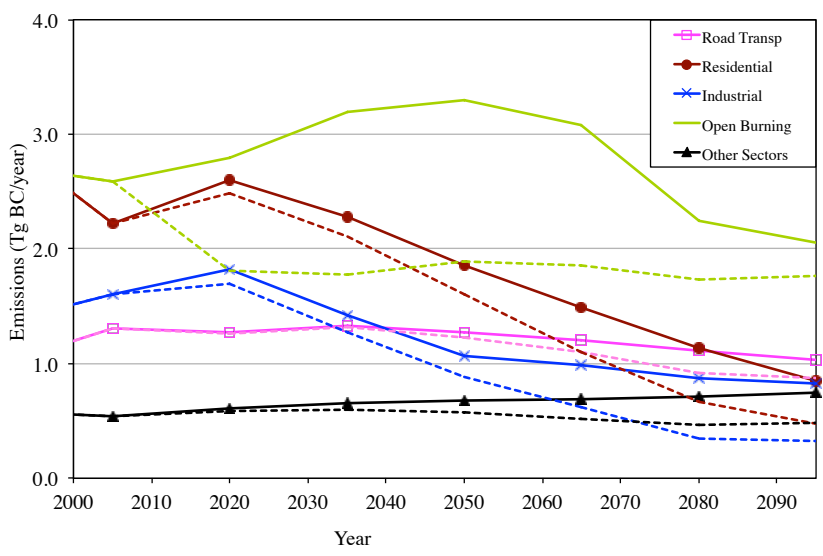

Fig. 2. Global black carbon emissions by sector under a reference case (solid lines) and RCP4.5 policy scenario (dotted lines).

outpace demand growth. The rate of deforestation also eventually slows as the rate of agricultural yield improvement becomes sufficient to match growth in food demand. While all of these changes are consistent with historical tends, their implementation implies sufficient investment along with necessary changes in infrastructure.

While global BC emissions from the transportation sector eventually begin to decrease, this decrease doesn't occur until later in the century. BC emissions from transport fall in OECD countries, while there is a general increase in developing countries. The approximate date of the emission peak for road transport in the reference scenario is 2035 for South and East Asia, 2050 in India, and 2070 in Africa (Fig. S6). While emission factors in GCAM are assumed to decrease over time, this decrease is countered with increased transportation demands. Liquid fuel consumption for road transport in developing countries doubled from 1990 to 2005 and, in this scenario, doubles again by 2035 , and yet again by 2080. Emission factors in all regions eventually converge to values below current OECD averages (see ESM).

Road transport emissions in the GCAM scenario are twice as large in 2050 as the B2 scenario from Yan et al. (2011), primarily due to larger fuel consumption growth in GCAM from 2030 to 2050, but also due to a somewhat lower rate of aggregate emission factor decrease in the GCAM scenario (see ESM). The Yan et al. (2011) emission projection, in turn, has a slower relative decrease in emissions over time compared to other similarly detailed projections due to consideration of "super-emitters" and the assumption of a later introduction of emission controls in Africa.

Organic carbon emissions are dominated by open burning (forests and grasslands) and the buildings sector. Total emissions increase over the next several decades in the reference scenario due to continued emissions from these sources, with a substantial increase in deforestation rates near mid-century in the reference scenario (Figs. S2, S4).
When compared to the reference scenario, emissions of all aerosols and precursors are lower under a climate policy scenario, as shown in Fig. 1 due to decreases in coal consumption and increases in the price of commercial biomass, which reduces direct end-use combustion of biomass.

Early in the 21st century, much of the reduction in black carbon emissions in the climate policy scenario is due to decreased open burning associated with deforestation (Fig. S5). By the end of the 21st century, most black carbon emission reductions come from energy-related sectors. Most of the change in organic carbon emissions under a climate policy is due to changes in open burning, due to the assumption that terrestrial carbon is valued at the same rate as fossil fuel carbon. In contrast, almost all the change in $\mathrm{SO}_{2}$ emissions due to a climate policy are from changes in fossil fuel combustion.

Future emissions in this reference case are still higher in 2100 than in 1850 for $\mathrm{BC}$ (and $\mathrm{SO}_{2}$ ). Even in the RCP4.5 policy scenario, emissions are higher in most sectors in 2100 as compared to 1850 . The only exceptions are $\mathrm{BC}$ and $\mathrm{OC}$ emissions from the buildings sector, which are lower in 2100 than in 1850 due to use of technologies with lower emission factors.

There are few long-term global scenarios of carbonaceous emissions to compare with these projections. The GCAM values are similar to global and regional values for the other RCP scenarios, with a slightly lower global near-term peak than the RCP2.6 scenario (Masui et al., 2011; Riahi et al., 2011; van Vuuren et al., 2011). Global BC and OC emissions in the reference scenario are larger in 2030 and 2050 than any of the scenarios in Streets et al. (2004); see ESM. The RCP4.5 emissions were also similar to several near-term scenarios for Asia in 2030 (Streets et al., 2010), although all of these newer scenarios were also higher than the estimates by Streets et al. (2004).

\section{Radiative forcing by aerosols}

\subsection{Radiative forcing parameterizations}

In order to examine the past and future role of aerosols we construct estimates of global top of the atmosphere (TOA) radiative forcing for each aerosol component. For well-mixed greenhouse gases and reflecting aerosols, the use of radiative forcing as a metric to compare climate implications, specifically temperature change, of different substances is accurate to about $\pm 25 \%$ (Berntsen et al., 2006; Forster et al., 2007). While the relationship between forcing and climate change for the absorbing aerosol black carbon differs more substantially from that for greenhouse gases, radiative forcing is still a reasonable measure of the relative impact of black carbon on planetary energy balance.

We will define high, medium, and low estimates of year 2000 forcing from $\mathrm{SO}_{2}, \mathrm{BC}$, and $\mathrm{OC}$ and cloud indirect 

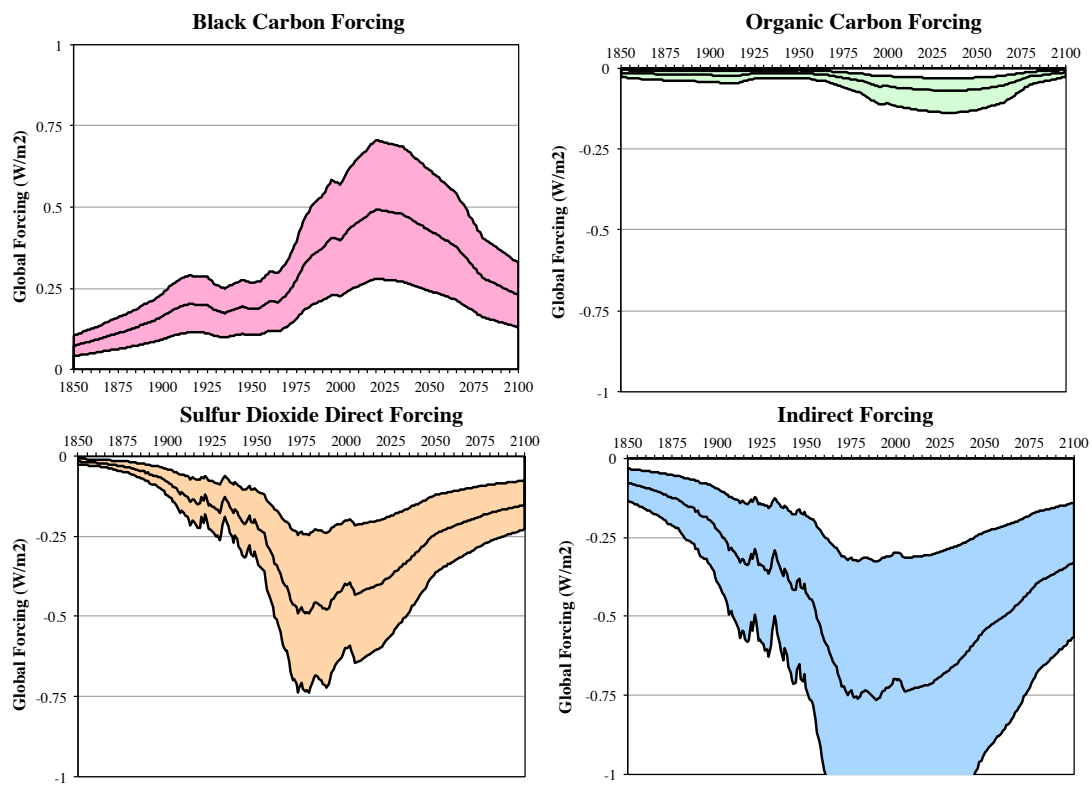

Fig. 3. Radiative forcing ranges for black carbon, organic carbon, sulfate aerosol, and indirect cloud forcing estimated by combining historical emissions estimates plus future emissions under the reference case scenario.

effects, with total aerosol forcing constrained using observational and pattern matching studies. This will allow an assessment of the implications of forcing uncertainty on past and future aerosol forcing pathways. When combined with the emission scenarios described above, forcing pathways from 1850 to 2100 are obtained for each forcing component as shown in Fig. 3. To illustrate plausible ranges of past and future aerosol forcing pathways, all combinations of high-, medium- and low-forcing assumptions for these four forcing components are constructed, giving 81 forcing cases.

Direct forcing was assumed to be proportional to global anthropogenic emissions for each aerosol species separately. By definition, forcing is a difference between a perturbed state and a background state, which is usually assumed to be preindustrial. Emissions are substantial even in 1850 for both black and organic carbon, due to emissions from forest and grassland fires and use of biomass in the residential sector. We define the preindustrial reference level for carbonaceous aerosols from open fires as the 1900 emission level from Lamarque et al. (2010) because this is the earliest value available in this time series. This value is larger than the preindustrial value used in Schulz et al. (2006). The choice of the preindustrial value from which forcing from carbonaceous aerosol emissions is calculated has only a modest impact on the results because of cancelation between $\mathrm{BC}$ and OC forcing from open burning.

For simplicity, we present forcing values calculated to be relative to a state with no anthropogenic emissions, not relative to a specific year. Anthropogenic emissions are defined as total emissions minus the assumed preindustrial value for open burning. This has little impact on the results due to the small absolute value for forcing in 1850 (see below).

We parameterize cloud indirect forcing as proportional to the natural log of total aerosol and precursor emissions (BC $+\mathrm{OC}+\mathrm{SO}_{2}$ ) in order to represent saturation of this forcing effect as emissions increase (e.g., Harvey and Kaufmann, 2002). Sulfate burden is represented as mass of $\mathrm{SO}_{2}$ since the factor of 1.8 difference in mass between $\mathrm{SO}_{2}$ and sulfate is offset by the fact that only about half of $\mathrm{SO}_{2}$ emissions forms sulfate. This parameterization does not capture numerous potential complications such as spatial dependences, chemical transformations (e.g., aging), interactions between different aerosol components, and different atmospheric lifetimes. Model and observational studies, however, have not explored these relationships sufficiently to provide a more complex parameterization. Indirect forcing is uncertain, resulting in large differences between models and between models and observational estimates (McComiskey and Feingold, 2008; Quaas et al., 2008; Penner et al., 2011; Wang et al., 2011).

High, medium, and low values for sulfur dioxide and cloud indirect effects are drawn from Forster et al. (2007). Forcing per unit emission for BC and OC is from Bond et al. (2011), with contained and open combustion emissions weighted to match the year 2000 RCP base-year emissions used here. Forcing from $\mathrm{BC}$ on snow is included in the $\mathrm{BC}$ direct component used here. While the forcing estimates in Forster et al. (2007) are nominally for year 2005 forcing, aerosol emission estimates assessed in Forster et al. (2007) were updated to the year 2000 at latest, so 2000 is used as the base year for forcing calculations. The forcing ranges are shown in Table 1. Forcings per unit emission have around a factor of 
Table 1. Assumed range for radiative forcing. Year 2000 anthropogenic emissions (total emissions - assumed preindustrial baseline) are $\mathrm{BC}: 5.7 \mathrm{TgC} ; \mathrm{OC}: 17.4 \mathrm{TgC} ; \mathrm{SO}_{2}: 111 \mathrm{TgSO}_{2}$.

\begin{tabular}{|c|c|c|c|}
\hline \multicolumn{4}{|c|}{ Year 2000 Forcing } \\
\hline & Low & Medium & High \\
\hline \multicolumn{4}{|c|}{ Global 2000 Forcing $\left(\mathrm{W} \mathrm{m}^{-2}\right)$} \\
\hline $\mathrm{BC}$ & 0.23 & 0.40 & 0.57 \\
\hline $\mathrm{OC}$ & -0.11 & -0.056 & -0.025 \\
\hline $\mathrm{SO}_{2} \mathrm{Dir}$ & -0.60 & -0.40 & -0.20 \\
\hline Cloud Indir & -1.2 & -0.70 & -0.30 \\
\hline \multicolumn{4}{|c|}{ Average Unit Forcing $\left(\mathrm{mW} \mathrm{m}^{-2} \mathrm{Tg}^{-1}\right)$} \\
\hline $\mathrm{BC}$ & 40 & 70 & 100 \\
\hline $\mathrm{OC}$ & -6.3 & -3.2 & -1.4 \\
\hline $\mathrm{SO}_{2} \mathrm{Dir}$ & -5.4 & -3.6 & -1.8 \\
\hline
\end{tabular}

two uncertainty. Although the emission-to-forcing relationship for aerosols varies by region (Berntsen et al., 2006; Koch et al., 2007; Bond et al., 2011) and possibly by climate state, forcing relationships are assumed to be identical for all sources, regions, and time periods in this work, as regional differences are lower than overall uncertainties. Total aerosol forcing is assumed to be equal to the sum of the four forcing components (Skeie et al., 2011).

Bond et al. (2013), hereinafter "Bounding-BC", recently assessed carbonaceous aerosol forcing. High and central BC values of direct forcing per emission used here (Table 1) are similar while the Bounding-BC lowest value is smaller, which would lead to a slightly larger range of overall forcing in our sensitivity studies below. The direct forcing-peremission values in Bounding-BC were also drawn from AeroCom models; they differ from the values used in this work mainly because Bounding-BC employed emission scaling, and emissions were increased in regions where aerosol had shorter lifetimes.

The central OC direct forcing value in Bounding-BC is $40 \%$ more negative than that used here, and the low/high range is also slightly (20-30\%) wider in the Bounding-BC report. The net effect is a potentially lower overall forcing from BC + OC. This could change some of the details of our results; however, since organic carbon forcing is very small compared to $\mathrm{BC}$ and $\mathrm{SO}_{2}$ forcing (Fig. 3), altering the forcing-per-emission for $\mathrm{OC}$ makes a small difference in overall forcing trajectories.

A large part of the reason for higher black carbon forcing in Bond et al. (2013) is the finding that BC burden needs to be increased to match atmospheric observations. Bond et al. also increased the OC burden proportionately, which results in smaller increase in net forcing as increased negative OC forcing offsets somewhat the increased BC forcing.

Emissions of aerosols and precursor components, particularly for carbonaceous aerosols, are also uncertain. Extend- ing this analysis to incorporate emission uncertainty would require an explicit representation of uncertainties for common driving forces and emission factors for the three emissions considered (BC, OC, and $\mathrm{SO}_{2}$ ), and this was beyond the scope of the present study. The aerosol-forcing trajectories presented here, therefore, represent a plausible range of forcing, given the historical and future evolution of aerosol emissions as represented in the scenarios used here.

While all components are uncertain, the largest absolute range is for the cloud indirect effect, followed by black carbon and sulfate direct forcing (Fig. 3). The direct forcing from black and organic carbon and sulfate over time follow directly from emissions pathways. Black carbon is the largest contributor to forcing uncertainty in the mid-19th century as anthropogenic emissions were significant even at this point in time. Direct forcing from sulfur dioxide is relatively small until the mid-20th century. Black carbon and sulfur dioxide forcing increase significantly in the last half of the 20th century. In this reference case scenario black carbon forcing remains substantial until it declines to $50-60 \%$ of the 2005 value by the end of the 21st century. Forcing from sulfur dioxide decreases over the 21 st century in the reference scenario, with a relatively rapid global decrease by mid-century.

Indirect (cloud) forcing is very uncertain and is potentially significant during the entire historical and future period considered. The assumption of a logarithmic dependence on emissions results in a cloud indirect forcing that is still substantial by the end of the 21 st century even though $\mathrm{SO}_{2}$ emissions have dropped by $60 \%$ from 2000 to 2100 . At present, sulfate is the dominant anthropogenic aerosol, and this remains the case throughout the 21 st century. In terms of anthropogenic emission mass, $\mathrm{SO}_{2}$ is $70-80 \%$ of the total $\left(\mathrm{SO}_{2}\right.$ $+\mathrm{BC}+\mathrm{OC}$ ) emission by mass over 2000-2100 in the reference scenario, and $80-90 \%$ in the RCP4.5 climate policy scenario. This fraction decreases prior to 1950 , and by the start of our analysis in 1850 anthropogenic OC emissions, largely from residential heating and cooking use, are comparable to $\mathrm{SO}_{2}$ emissions (although the uncertainty in $\mathrm{OC}$ emissions at this point is very large). Analysis of the strength of the indirect effect over time from models that include multiple relevant species would provide valuable guidance for the development of improved parameterizations of this effect.

Nitrate and secondary organic aerosol (SOA) will also impact forcing. While nitrate aerosol forcing is currently thought to be relatively small, its role seems likely to become more important in the future as sulfur dioxide emissions decrease (Liao and Seinfeld, 2005; Bellouin et al., 2011). Bellouin et al. (2011) find that nitrate aerosols increase negative aerosol forcing by $0.2 \mathrm{~W} \mathrm{~m}^{-2}$ from 2000 to 2090 for the RCP4.5 scenario, which means that aerosol cooling could be slightly underestimated in the projections developed here. Myhre et al. (2009) find current anthropogenic SOA forcing to be $-0.09 \mathrm{~W} \mathrm{~m}^{-2}$. Since anthropogenic NMVOC emissions decline over the 21 st century in these scenarios, anthropogenic SOA forcing may decline, although SOA would also 
Table 2. Total aerosol forcing ranges (see text) estimated from several studies. Except where noted, ranges represent a 5-95\% range.

\begin{tabular}{lrrr}
\hline \multirow{2}{*}{ Source } & \multicolumn{3}{c}{ Total Aerosol Forcing } \\
\cline { 2 - 4 } & Low & Central & High \\
\hline Murphy et al. (2009) - 2 $\sigma$ & -1.9 & -1.1 & -0.3 \\
Andronova and Schlesinger (2001) & -1.3 & -0.9 & -0.5 \\
Stott et al. (2006) & -1.4 & -0.9 & -0.4 \\
Forest et al. (2006) & $-0.7^{*}$ & -0.5 & -0.1 \\
Shindell and Faluvegi (2009) & -1.8 & -1.3 & $-0.8^{*}$ \\
Composite total aerosol (used herein) & -1.6 & & -0.4 \\
\hline *Values exclude from calculation of the composite range used in this work. &
\end{tabular}

be impacted by any changes in biogenic emissions due to future land-use and climate changes.

\subsection{Total aerosol forcing constraints}

We discuss in this section constraints on total aerosol forcing. Boucher and Haywood (2001) and Forster et al. (2007) independently combine ranges for each forcing component to estimate a $90 \%$ range for circa 2000 aerosol forcing of -2.2 to $-0.5 \mathrm{~W} \mathrm{~m}^{-2}$, with a central value of $-1.3 \mathrm{~W} \mathrm{~m}^{-2}$. This range, however, is not constrained by observations (Anderson et al., 2003). A number of studies have attempted to constrain aerosol forcing using observations, as summarized in Table 2.

Murphy et al. (2009), who use observational data and energy balance calculations to constrain total aerosol forcing, estimate a total aerosol forcing contribution of $-1.1 \pm 0.4$ $(1 \sigma) \mathrm{W} \mathrm{m}^{-2}$ over the period 1970-2000. This calculation is particularly useful because it is not based on modeling results.

A number of attribution, or inversion, studies, which statistically evaluate the match between modeled patterns of climate change and observations, have found that a net negative aerosol forcing is required to match observations. The inversion studies generally consider temperature records over most of the 20th century, which includes the observed changes from 1950 to 1970, a period of rapid aerosol increase. While the central values of the studies in Table 2 are similar, except for Forest et al. (2006), the bounding values are less well defined. Stott et al. (2006) estimate a $90 \%$ bound for net aerosol forcing of -0.4 to $-1.4 \mathrm{~W} \mathrm{~m}^{-2}$, which is noteworthy for combining results from three General Circulation Models (GCMs). Overall, the high bound (small absolute value) from these studies ranges from -0.1 to $-0.8 \mathrm{~W} \mathrm{~m}^{-2}$, and the low bound (large absolute value) ranges from -0.7 to $-1.9 \mathrm{~W} \mathrm{~m}^{-2}$. The net result is a large uncertainty in the bounding values' total forcing.

We have not included the recent estimate from Hansen et al. (2011), which is based largely on data from 2005 to 2010 . Hansen et al. (2011) derive a central value for aerosol forcing of $-1.6 \mathrm{~W} \mathrm{~m}^{-2}$. This is larger than the central values from previous estimates (Table 2) and also difficult to reconcile with observed temperature change to date (Andronova and Schlesinger, 2001; Forest et al., 2006) ${ }^{1}$.

Comparing these estimates is complicated by differences in the time period covered. The start of the time period considered varies from 1765 to 1880 , while the ending point varies from 1997 to 2007. A change in the start of the preindustrial period could result in a difference of up to $0.2 \mathrm{~W} \mathrm{~m}^{-2}$ in the preindustrial baseline. An additional issue is that many of the methods considered assume either normal or at least symmetric uncertainty bounds, which may not be realistic assumptions (e.g., Andronova and Schlesinger, 2001).

Given the difficulties in comparing these different studies, we select bounding values that are inclusive rather than restrictive. We choose low and high bounding values as the average of the low and high values from the studies in Table 2, excluding one outlier value in each case $^{2}$. Excluding the outlier values widens the resulting range, which is appropriate given the lack of agreement between these studies. The result is a range for total aerosol forcing of -1.6 to $-0.4 \mathrm{~W} \mathrm{~m}^{-2}$. This range is smaller than that from Forster et al. (2007) which is not constrained by observations and is larger than the range found in climate models (Kiehl, 2007). Note that some of the model values did not include aerosol indirect effects. While this procedure is somewhat subjective, a more complex methodology is not warranted given the differences between the study approaches and their substantial disagreement in terms of bounding values.

The estimates in Table 2 are also, formally, not estimates of aerosol forcing but of forcing from all factors not explicitly accounted for in each specific analysis (or, at least, factors that are statistically similar to aerosol forcing). All of these studies account for the forcing from solar irradiance changes, volcanic aerosols, and tropospheric and stratospheric ozone. A number of additional effects, however, can complicate the comparisons including so-called semi-direct forcings (Andrews and Forster, 2008) and forcings due to land-use changes and stratospheric water vapor changes. A reanalysis of these literature results taking into account the slightly different boundary conditions in each study would be helpful, but is beyond the scope of this present work.

Finally, further discussion in this paper addresses forcing from sulfate and carbonaceous aerosols and cloud indirect effects. To obtain bounds for the combination of these components, we need to account for the contributions from mineral dust and nitrate aerosols, which are together estimated to have an anthropogenic forcing of $-0.2 \mathrm{~W} \mathrm{~m}^{-2}$, albeit with

\footnotetext{
${ }^{1}$ We note that Hansen et al. (2011) assume that aerosol forcing was constant from 1970 to 2000 , while our central estimate is that aerosol forcing declined by $20 \%$ over this period. It is not clear if this can explain the difference between the Hansen et al. aerosol forcing estimate and the other studies cited here.

${ }^{2}$ We exclude from the average the low bound from Forest et al. (2006) and the high bound from Shindell and Faluvagi (2009) since these values are closer to the average central value than the bounding values from the other studies.
} 
Global Aerosol Forcing-RCP4.5

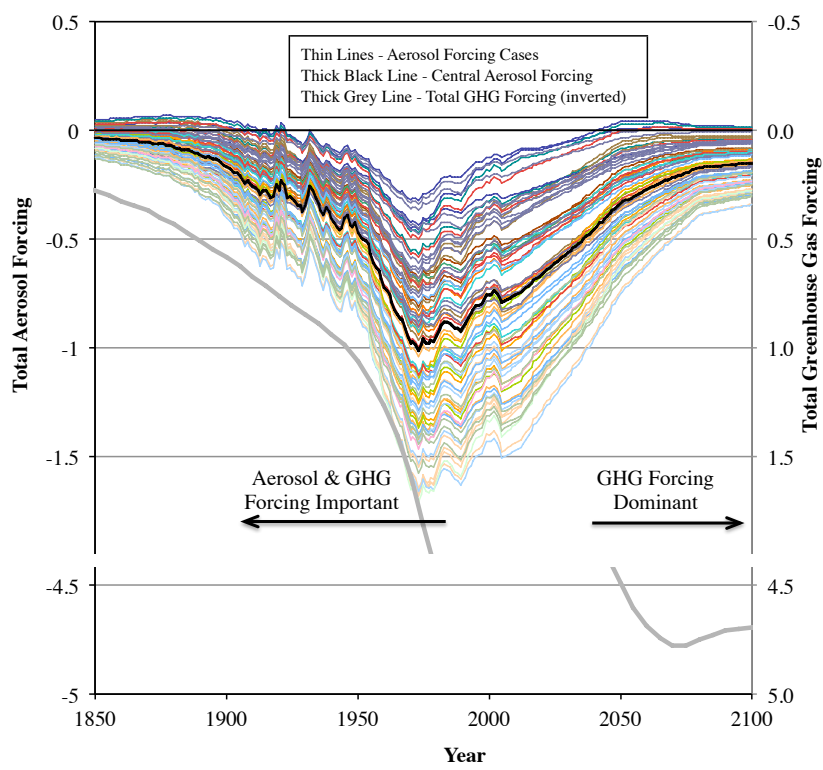

Fig. 4. Total aerosol forcing, including sulfate, black carbon, organic carbon, and cloud indirect, for different combinations of current period forcing assumptions as shown in Table 1 for the RCP4.5 policy scenario (with different colors for each forcing combination). The central forcing case is shown as the thick black line, and global forcing from greenhouse gases $\left(\mathrm{CO}_{2}, \mathrm{CH}_{4}, \mathrm{~N}_{2} \mathrm{O}\right.$, halocarbons, and tropospheric ozone) is also shown for comparison on an inverted scale. Note the post-2050 change of vertical scale for GHG forcing.

a large uncertainty range (Forster et al., 2007). Again wishing to be inclusive, we set the allowed range for total forcing from the components considered in this paper to be -1.6 to $-0.2 \mathrm{~W} \mathrm{~m}^{-2}$. This retains $-1.6 \mathrm{~W} \mathrm{~m}^{-2}$ as one bound, implicitly assuming these additional components are negligible in this case, but shifts the other bound to allow for the possibility that very low absolute forcing from the components considered in this work could be augmented by additional negative forcing from mineral dust and nitrate aerosols. Changes in other forcings over this period, such those associated with stratospheric water vapor and land-use changes, could also impact aerosol forcing estimates. We have not attempted to take such changes into account, particularly given the different methodologies used in these works, and this might add additional uncertainty.

\subsection{Global radiative forcing pathways}

A variety of total net aerosol forcing pathways result from the large uncertainty in individual components plus the effect of adding uncertain negative and positive components. Figure 4 shows the set of forcing pathways that result from linearly combining the three direct forcing components with cloud indirect forcing for combinations of high-, medium, and low-forcing assumptions. Ten pathways with forcing outside the observational estimate of total forcing, -0.2 to $-1.6 \mathrm{~W} \mathrm{~m}^{-2}$ averaged over 1970-2000, were removed from the analysis (see ESM).

Global forcing from greenhouse gases is also shown for comparison (with scale inverted), using values from the MAGICC model (Thomson et al., 2011). GHG forcing in this work is taken to be the sum of forcing from well-mixed GHGs $\left(\mathrm{CO}_{2}, \mathrm{~N}_{2} \mathrm{O}, \mathrm{CH}_{4}\right.$, and fluorinated gases) and tropospheric ozone.

The range of aerosol forcing is summarized over several time periods in Table 3. In 1850, net aerosol forcing is dominated by direct forcing from black carbon and cloud indirect effects. These are of opposite sign, and both uncertain, leading to a small net forcing in this year. Greenhouse gas forcing of $0.3 \mathrm{~W} \mathrm{~m}^{-2}$ in 1850 , dominated by $\mathrm{CO}_{2}$ and $\mathrm{CH}_{4}$ forcing, is larger than net aerosol forcing. During the last half of the 19th century there was an increase in net aerosol cooling effect in most cases, i.e., a forcing change over this period ranging from 0 to $-0.3 \mathrm{~W} \mathrm{~m}^{-2}$, depending on aerosol forcing assumptions (Table 3 ).

The net negative forcing by aerosols increased further during the first half of the 20th century by an additional -0.1 to $-0.5 \mathrm{~W} \mathrm{~m}^{-2}$, again depending on aerosol assumptions. The ratio of aerosol to greenhouse gas forcing over this period ranged from negligible to $80 \%$ of greenhouse gas forcing offset by aerosols (Fig. S10).

Aerosol emissions and the resulting cooling increased even further from 1950 to 1970 . All cases exhibit an increase in negative forcing over this period, ranging from -0.2 to $-0.8 \mathrm{~W} \mathrm{~m}^{-2}$. The increase in aerosol forcing from 1950 to 1970 brings the central estimate of total aerosol forcing to nearly $70 \%$ of estimated forcing from greenhouse gases. The ratio of aerosol to GHG forcing varies from $20 \%$ to $100 \%$ over the 1950-1970 period, depending on aerosol forcing assumptions. Increasing aerosol forcing over this period appears to have contributed to flattening of global temperature increase over this time, which provides a portion of the observational constraint on total aerosol forcing (Table 2).

During the last three decades of the 20th century, a decrease in sulfur dioxide emissions, combined with continued emissions of black carbon, results in a range of net forcing changes. Depending on the assumed strength of the different components, net aerosol forcing from 1970 through 2000 ranges from nearly no change to a $+0.4 \mathrm{~W} \mathrm{~m}^{-2}$ increase in radiative forcing, or net warming. Warming is associated with high or medium black carbon forcing together with low-medium assumptions for sulfur dioxide and cloud indirect forcing.

As the 21 st century proceeds, aerosol forcing decreases and greenhouse gas forcing becomes the globally dominant forcing agent. While the absolute magnitude of total aerosol forcing ranges from 5 to $50 \%$ of the forcing from greenhouse gases in 2000, this range decreases to $0-15 \%$ of the RCP4.5 forcing in 2050 , and $0-7 \%$ by 2100 . Even in a counterfactual case where aerosol emissions remained at their 2000 
Table 3. Central and range for estimated change in aerosol forcing $\left(\mathrm{SO}_{2}, \mathrm{BC}, \mathrm{OC}\right.$, cloud indirect) over specific time periods, for the reference and RCP4.5 policy scenarios. Total greenhouse gas forcing in the RCP4.5 scenario (see Fig. 4) is also shown.

\begin{tabular}{|c|c|c|c|c|c|c|c|c|c|c|c|}
\hline & \multicolumn{5}{|c|}{ Historical } & \multicolumn{3}{|c|}{ Reference } & \multicolumn{3}{|c|}{$\mathrm{RCP} 4.5$} \\
\hline \multicolumn{12}{|c|}{ Aerosol Forcing Change $\left(\mathrm{W} \mathrm{m}^{-2}\right)$} \\
\hline & $1850-1900$ & 1900-1950 & 1950-1970 & 1970-2000 & & $2000-2050$ & $2050-2100$ & $2000-2100$ & $2000-2050$ & $2050-2100$ & $2000-2100$ \\
\hline Maximum & 0.0 & -0.1 & -0.2 & 0.4 & & 0.5 & 0.4 & 0.8 & 0.7 & 0.4 & 1.1 \\
\hline Median & -0.1 & -0.3 & -0.5 & 0.2 & & 0.3 & 0.2 & 0.5 & 0.4 & 0.2 & 0.6 \\
\hline Minimum & -0.3 & -0.5 & -0.8 & 0.1 & & 0.1 & -0.1 & 0.1 & 0.1 & 0.0 & 0.1 \\
\hline \multicolumn{12}{|c|}{ Absolute Aerosol Forcing Relative to Preindustrial } \\
\hline & 1850 & 1900 & 1950 & 1970 & 2000 & 2050 & 2100 & & 2050 & 2100 & \\
\hline Maximum & 0.1 & 0.1 & 0.0 & -0.2 & 0.0 & 0.2 & 0.1 & & 0.1 & 0.1 & \\
\hline Median & 0.0 & -0.2 & -0.5 & -1.0 & -0.8 & -0.5 & -0.3 & & -0.3 & -0.1 & \\
\hline Minimum & -0.1 & -0.5 & -1.0 & -1.9 & -1.7 & -1.2 & -0.7 & & -0.9 & -0.4 & \\
\hline GHG Forcing & 0.3 & 0.6 & 1.1 & 1.6 & 2.9 & 5.1 & 7.4 & & 4.5 & 4.7 & \\
\hline
\end{tabular}

values, aerosol forcing would be only $0-20 \%$ of reference case GHG forcing in 2100. Note that global $\mathrm{SO}_{2}$ emissions in 2010 are estimated to be below year 2000 values (Klimont et al., 2013).

The net change in aerosol forcing over the 21 st century is positive in all cases, ranging from +0.1 to $+0.8 \mathrm{~W} \mathrm{~m}^{-2}$ in the reference scenario. That is, the reduction in the large negative forcing due to aerosols causes a positive net change in forcing over this period. By the end of the 21st century, net aerosol forcing relative to preindustrial conditions ranges from +0.1 to $-0.7 \mathrm{~W} \mathrm{~m}^{-2}$, while GHG forcing increases to $>7 \mathrm{~W} \mathrm{~m}^{-2}$ in the reference case.

The latter part of the 20th century marked an important transition in the history of anthropogenic forcing. Prior to this period, aerosol forcing played a key role in the net radiative balance, as net negative aerosol forcing offset a significant portion of greenhouse gas forcing. From about 1970, the combination of aerosol emission controls and shifts in technologies slowed or decreased growth in aerosol forcing, while continued increases in fuel consumption led to steady atmospheric accumulation of greenhouse gases. By the current time ( 2012), the proportion of greenhouse gas forcing offset by aerosols is only $20 \%$ (with a range of 5-45\%). These changes have precipitated a new era, where greenhouse gases again dominate anthropogenic forcing.

\subsection{Aerosol forcing and climate policy}

As discussed above, emissions of aerosols decrease relative to the reference scenario under implementation of a climate policy. As a result, the range and magnitude of aerosol forcing is smaller in the RCP4.5 policy case. End-of-century aerosol forcing ranges from 0 to $-0.4 \mathrm{~W} \mathrm{~m}^{-2}$, which means a net forcing increase due to aerosols of 0.1 to $1.1 \mathrm{~W} \mathrm{~m}^{-2}$ during the 21 st century. Greenhouse gas emissions also decrease relative to the reference case, but still dominate forcing over the 21 st century (Fig. S11).

Forcing changes between the reference and policy scenarios are determined largely by the net change in emissions from energy and industrial activities. The net impact of landuse aerosol emissions is relatively small in terms of global radiative forcing because the positive radiative forcing of black carbon from open burning is largely offset by the negative forcing from organic carbon emissions.

Because emissions resulting in both positive and negative forcing decrease in the policy scenario relative to the reference scenario, the net effect depends on aerosol forcing assumptions. Aerosol forcing responds more quickly to emission changes as compared to GHG concentrations, so the change in aerosol forcing can be a substantial fraction of greenhouse gas forcing change in early years (Fig. S12).

In most cases, aerosol emission changes due to a climate policy result in a positive forcing change, or warming, relative to the reference case. Even in the case with the strongest total aerosol cooling, however, the reduction in greenhouse gas forcing exceeds the additional warming due to aerosol decreases by 2025 (Fig. 5).

In cases where black carbon forcing is assumed to be relatively strong relative to other components, climate policy can also result in a near-term net aerosol cooling relative to the reference case (e.g., cases in Fig. 5 with a negative sign; see also SM). The largest net forcing decrease, however, is less than $0.1 \mathrm{~W} \mathrm{~m}^{-2}$. This forcing decrease generally transitions to a net forcing increase, or warming, by the end of the century, however, as decreases in negative forcing components outweigh decreases in black carbon.

The absolute and relative impact of aerosol forcing changes due to the climate policy declines through the $21 \mathrm{st}$ century. In 2030, the forcing change due to aerosols ranges from a $75 \%$ offset of the GHG forcing decrease (e.g., warming relative to the impact of aerosols in the reference case) in that year to a $30 \%$ enhancement of the GHG forcing reduction (Fig. S9). By 2050 this range reduces to $+40 \%$ to $-11 \%$. Aerosol effects, therefore, can substantially alter the net forcing pathway over the first half the 21 st century. Aerosols offset only $0-9 \%$ of the GHG forcing reduction due to the climate policy by 2100 . 


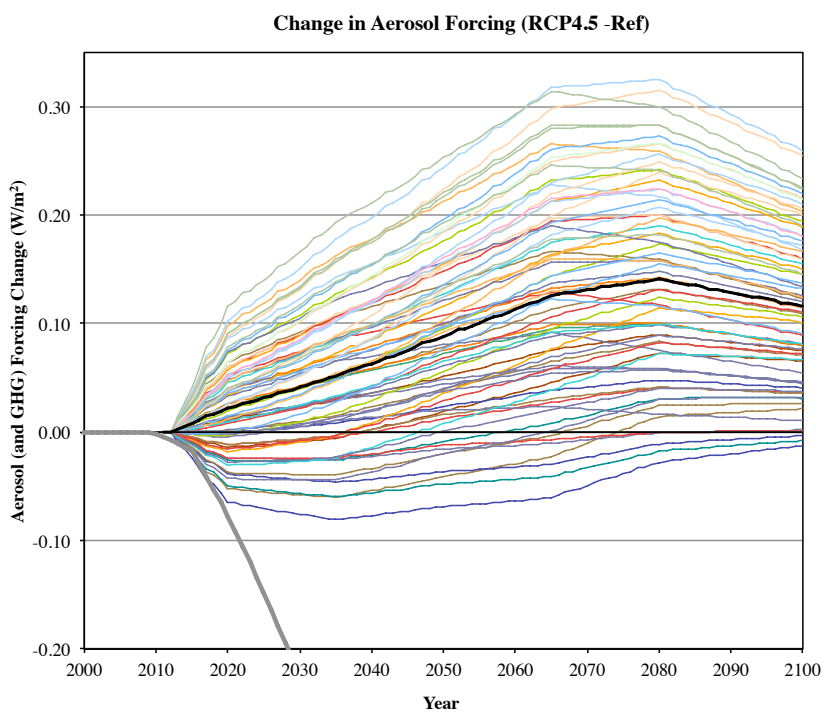

Fig. 5. Total aerosol forcing change between the reference and RCP4.5 climate policy scenario for the suite of aerosol forcing cases (central forcing assumptions, thick black line). A positive value indicates a positive forcing change (e.g., warming) under the RCP4.5 climate policy scenario as compared to the reference case. Reference case aerosol emissions were assumed through 2012. The thick grey line shows the change in greenhouse gas forcing.

\section{Discussion and conclusion}

We show that a wide variety of forcing pathways over the historical period are consistent with current constraints on aerosol forcing. The largest absolute and relative impact of aerosols on climate occurred between 1950 and 1970, where the change in total aerosol forcing over this period ranged from -0.2 to $-0.8 \mathrm{~W} \mathrm{~m}^{-2}$.

While aerosols have historically had a large role compared with greenhouse gases, aerosol forcing relative to well-mixed greenhouse gas forcing has been decreasing for the past three decades. By the first decade of the 21st century, the impact of aerosols is almost certainty less than that of greenhouse gases, and likely only a small fraction of greenhouse gas forcing. Anthropogenic forcing in the 21st century will again be dominated by greenhouse gases, with a projected decrease in the absolute and relative influence of aerosols.

Changes in aerosol emissions over the 21 st century result in a radiative forcing increase of $0.1 \mathrm{~W} \mathrm{~m}^{-2}$ to $0.8 \mathrm{~W} \mathrm{~m}^{-2}$ for the reference scenario, depending on assumptions for present-day aerosol forcing. By the mid-21st century, aerosol forcing in the GCAM reference scenario is projected to offset at most $25 \%$, and more likely only $10 \%$, of well-mixed greenhouse gas forcing. The regional signature of future climate change will increasingly be that of well-mixed greenhouse gases (Meehl et al., 2007; Sect. 10.3.2).

In the near term, we find that the co-incident changes in aerosol emissions due to a climate policy can either enhance or offset these greenhouse gas reductions, relative to the ref- erence case with no climate policy, depending on the assumed forcing from different aerosol components. If black carbon forcing is assumed to be strong relative to cooling effects, the aerosol emission changes due to a climate policy could result in a globally small net-near-term cooling influence. In nearly all cases, however, the aerosol changes due to a climate policy cause a net relative warming by the end of the century (Fig. 5).

Over the long term, a reduction in aerosol forcing is expected due to greater demand for cleaner air as a result of increasing incomes in developing countries, and this reduction is even more likely under a climate policy scenario. The analysis here used only one policy case. While there is a very wide range of potential future emission scenarios in the $a b$ sence of a climate policy, the range for emissions of conventional air pollutants under the assumption of a successful implementation of a climate policy is much more constrained (Smith et al., 2005; van Vuuren et al., 2008), because reducing $\mathrm{CO}_{2}$ emissions requires a shift to technologies with inherently low emissions of aerosols and precursor compounds. While the rate of future aerosol emission declines is uncertain, the overall pattern and finding of reduced aerosol emissions by mid-century is robust across projections of future emissions under a climate policy.

These results also have implications for the framing of mitigation of climate change by focusing on black carbon emissions. Energy-related black carbon emissions decline by only $8 \%$ from 2000 to 2050 in the reference case, and enhancing these reductions could reduce positive forcing. Under a comprehensive climate policy, fuel use will shift away from coal in industrial and residential sectors, causing additional black carbon reductions as a side effect. In the climate policy case considered here, energy-related black carbon emissions decline by $20 \%$ over the same period. The effect of climate policies on air pollutant emissions needs to be taken into account in order to avoid double-counting potential reductions.

While observational constraints on total aerosol forcing rule out very large negative values, current estimates of the high and low bounds for total aerosol forcing vary widely (Table 2), to the point of being inconsistent in some cases. A more robust comparison of historical forcing estimates that accounts for differences in methodology, assumptions, and time period would be useful to understand why bounding values vary so substantially, and perhaps to ultimately provide a tighter constraint on current aerosol forcing.

Techniques that bound aerosol forcing by decade may offer an additional methodology to constrain aerosol forcing due to different relative changes over time (Fig. S13). The ratio of forcing over the decade of the 1970s to that in the $1990 \mathrm{~s}$ in our analysis, for example, ranges from 1.0 to 2.0 , that is from nearly the same to a factor of two decrease. The largest differences in total aerosol forcing between the 1970s and the 1990s occur in cases with a combination of strong aerosol indirect forcing together with medium to strong black 
carbon forcing. Observational bounds on aerosol forcing by decade might be able to better constrain aerosol forcing.

We note that there is a wider range of potential forcing pathways than presented here. We have not considered uncertainty in historical emissions, which is particularly large for carbonaceous aerosols. Changing emission-forcing relationships over time and by region will also result in additional uncertainty. Nitrate aerosols, SOA, interactions with reactive gases, and the impact of changes in climate will also alter aerosol forcing. These were not considered as simple representations of the potential magnitude of these effects and their changes over time have not been developed, nor have they been compared across different climate-chemistry models.

\section{Supplementary material related to this article is available online at http://www.atmos-chem-phys.net/14/ 537/2014/acp-14-537-2014-supplement.pdf.}

Acknowledgements. Work by S. Smith on this project was supported by the Climate Change Division, US Environmental Protection Agency (EPA). T. C. Bond was supported by the National Science Foundation under grant ATM-0852775. Pacific Northwest National Laboratory is operated by Battelle for the US Department of Energy under contract DE-AC05-76RL01830. The views expressed in this paper are those of the authors alone.

Edited by: M. K. Dubey

\section{References}

Anderson, T. L., Charlson, R. J., Schwartz, S. E., Knutti, R., Boucher, O., Rodhe, H., and Heintzenberg, J.: Climate forcing by Aerosols - a hazy picture, Science, 300, 1103-1104, 2003.

Andrews, T. and Forster, P. M.: $\mathrm{CO}_{2}$ forcing induces semi-direct effects with consequences for climate feedback interpretations, Geophys. Res. Lett., 35, L04802, doi:10.1029/2007GL032273, 2008.

Andronova, N. G. and Schlesinger, M. E.: Objective estimation of the probability density function for climate sensitivity, J. Geophys. Res., 106, 22605-22611, doi:10.1029/2000JD000259, 2001

Bellouin, N., Rae, J., Jones, A., Johnson, C., Haywood, J., and Boucher, O.: Aerosol forcing in the Climate Model Intercomparison Project (CMIP5) simulations by HadGEM2-ES and the role of ammonium nitrate, J. Geophys. Res., 116, D20206, doi:10.1029/2011JD016074, 2011.

Berntsen, T., Fuglestvedt, J. S., Myhre, G., Stordal, F., and Berglen, T. F.: Abatement of greenhouse gases: Does Location Matter?, Clim. Change, 74, 377-411, doi:10.1007/s10584-006-0433-4, 2006.

Bond, T. C., Streets, D. G., Yarber, K. F., Nelson, S. M., Woo, J.-H., and Klimont, Z.: A technology-based global inventory of black and organic carbon emissions from combustion, J. Geophys. Res., 109, D14203, doi:10.1029/2003jd003697, 2004.

Bond, T. C., Bhardwaj, E., Dong, R., Jogani, R., Jung, S., Roden, C., Streets, D. G., and Trautmann, N. M.: Historical emissions of black and organic carbon aerosol from energy-related combustion, 1850-2000, Global Biogeochem. Cy., 21, GB2018, doi:10.1029/2006GB002840, 2007.

Bond, T. C., Zarzycki, C., Flanner, M. G., and Koch, D. M.: Quantifying immediate radiative forcing by black carbon and organic matter with the Specific Forcing Pulse, Atmos. Chem. Phys., 11, 1505-1525, doi:10.5194/acp-11-1505-2011, 2011.

Bond, T. C., Doherty, S. J., Fahey, D. W., Forster, P. M., Berntsen, T., DeAngelo, B. J., Flanner, M. G., Ghan, S., Karcher, B., Koch, D., Kinne, S., Kondo, Y., Quinn, P. K., Sarofim, M. C., Schultz, M. G., Schulz, M., Venkataraman, C., Zhang, H., Zhang, S., Bellouin, N., Guttikunda, S. K., Hopke, P. K., Jacobson, M. Z., Kaiser, J. W., Klimont, Z., Lohmann, U., Schwarz, J. P., Shindell, D., Storelvmo, T., Warren, S. G., and Zender, C. S.: Bounding the role of black carbon in the climate system: A scientific assessment, J. Geophys. Res.-Atmos., 118, 5380-5552, doi:10.1002/jgrd.50171, 2013.

Boucher, O. and Haywood, J.: On summing the components of radiative forcing of climate change, Clim. Dynam., 18, 297-302, doi:10.1007/s003820100185, 2001.

Charlson, R. J., Langer, J., Rodhe, H., Leovy, C. B., and Warren, S. G.: Perturbation of the Northern Hemisphere radiative balance by backscattering from anthropogenic sulfate aerosols, Tellus, 43, 152-163, 1991.

Clarke, L., Edmonds, J., Jacoby, H., Pitcher, H., Reilly, J., and Richels, R.: Scenarios of Greenhouse Gas Emissions and Atmospheric Concentrations. Sub-report 2.1A of Synthesis and Assessment Product 2.1 by the U.S. Climate Change Science Program and the Subcommittee on Global Change Research, Department of Energy, Office of Biological \& Environmental Research, Washington D.C., USA, 154 pp., 2007.

Fernandes, S. D., Trautmann, N. M., Streets, D. G., Roden, C. A., and Bond, T. C.: Global biofuel use, 1850-2000, Global Biogeochem. Cy., 21, GB2019, doi:10.1029/2006gb002836, 2007.

Forest, C. E., Stone, P. H., and Sokolov, A. P.: Estimated PDFs of climate system properties including natural and anthropogenic forcings, Geophys. Res. Lett., 33, L01705, doi:10.1029/2005GL023977, 2006.

Forster, P., Ramaswamy, V., Artaxo, P., Berntsen, T., Betts, R., Fahey, D. W., Haywood, J., Lean, J., Lowe, D. C., Myhre, G., Nganga, J., Prinn, R., Raga, G., Schulz, M., and Van Dorland, R.: Changes in Atmospheric Constituents and in Radiative Forcing, in: Climate Change 2007: The Physical Science Basis. Contribution of Working Group I to the Fourth Assessment Report of the Intergovernmental Panel on Climate Change, edited by: Solomon, S., Qin, D., Manning, M., Chen, Z., Marquis, M., Averyt, K. B., Tignor, M., and Miller, H. L., Cambridge University Press, Cambridge, United Kingdom and New York, NY, USA, 2007.

Hansen, J., Sato, M., Kharecha, P., and von Schuckmann, K.: Earth's energy imbalance and implications, Atmos. Chem. Phys., 11, 13421-13449, doi:10.5194/acp-11-13421-2011, 2011.

Harvey, L. D. D. and Kaufmann, R. K.: Simultaneously constraining climate sensitivity and aerosol radiative forcing, J. Climate, 15, 2837-2861, 2002. 
Kiehl, J. T.: Twentieth century climate model response and climate sensitivity, Geophys. Res. Lett., 34, L22710, doi:10.1029/2007GL031383, 2007.

Kiehl, J. T. and Briegleb, B. P.: The relative role of sulfate aerosols and greenhouse gases in climate forcing, Science 260, 311-314, 1993.

Klimont, Z., Smith, S. J., and Cofala, J.: The last decade of global anthropogenic sulfur dioxide: 2000-2011 emissions, Environ. Res. Lett., 8, 014003, doi:10.1088/1748-9326/8/1/014003, 2013.

Koch, D., Bond, T. C., Streets, D., Unger, N., and van der Werf, G. R.: Global impacts of aerosols from particular source regions and sectors, J. Geophys. Res., 112, D02205, doi:10.1029/2005JD007024, 2007.

Lamarque, J.-F., Bond, T. C., Eyring, V., Granier, C., Heil, A., Klimont, Z., Lee, D., Liousse, C., Mieville, A., Owen, B., Schultz, M. G., Shindell, D., Smith, S. J., Stehfest, E., Van Aardenne, J., Cooper, O. R., Kainuma, M., Mahowald, N., McConnell, J. R., Naik, V., Riahi, K., and van Vuuren, D. P.: Historical (1850-2000) gridded anthropogenic and biomass burning emissions of reactive gases and aerosols: methodology and application, Atmos. Chem. Phys., 10, 7017-7039, doi:10.5194/acp10-7017-2010, 2010.

Li, C., Zhang, Q., Krotkov, N., Streets, D. G., He, K., Tsay, S.C., and Gleason, J. F.: Recent large reduction in sulfur dioxide emissions from Chinese power plants observed by the Ozone Monitoring Instrument, Geophys. Res. Lett., 37, L08807, doi:10.1029/2010GL042594, 2010.

Liao, H., and Seinfeld, J. H.: Global impacts of gas-phase chemistry- aerosol interactions on direct radiative forcing by anthropogenic aerosols and ozone, J. Geophys. Res., 110, D18208, doi:10.1029/2005JD005907, 2005.

Lu, Z., Zhang, Q., and Streets, D. G.: Sulfur dioxide and primary carbonaceous aerosol emissions in China and India, 1996-2010, Atmos. Chem. Phys., 11, 9839-9864, doi:10.5194/acp-11-98392011, 2011.

Masui, T., Matsumoto, K., Hijioka, Y., Kinoshita, T., Nozawa, T., Ishiwatari, S., Kato, E., Shukla, P. R., Yamagata, Y., and Kainuma, M.: An emission pathway for stabilization at $6 \mathrm{~W} \mathrm{~m}^{-2}$ radiative forcing, Clim. Change, 109, 59-76, 2011.

McComiskey, A. and Feingold, G.: Quantifying error in the radiative forcing of the first aerosol indirect effect, Geophys. Res. Lett., 35, L02810, doi:10.1029/2007GL032667, 2008.

Meehl, G. A., Stocker, T. F., Collins, W. D., Friedlingstein, P., Gaye, A. T., Gregory, J. M., Kitoh, A., Knutti, R., Murphy, J. M., Noda, A., Raper, S. C. B., Watterson, I. G., Weaver, A. J., and Zhao, Z.-C.: Global Climate Projections, in: Climate Change 2007: The Physical Science Basis. Contribution of Working Group I to the Fourth Assessment Report of the Intergovernmental Panel on Climate Change, edited by: Solomon, S., Qin, D., Manning, M., Chen, Z., Marquis, M., Averyt, K. B., Tignor, M., and Miller, H. L., Cambridge University Press, Cambridge, United Kingdom and New York, NY, USA, 2007.

Mieville, A., Granier, C., Liousse, C., Guillaume, B., Mouillot, F., Lamarque, J.-F., Grégoire, J.-M., and Pétron, G.: Emissions of gases and particles from biomass burning during the 20th century using satellite data and an historical reconstruction, Atmos. Environ., 44, 1469-1477, 2010.

Moss, R. H., Edmonds, J. A., Hibbard, K., Carter, T., Emori, S., Kainuma, M., Kram, T., Manning, M., Meehl, J., Mitchell, J.,
Nakicenovic, N., Riahi, K., Rose, S., Smith, S. J., Stouffer, R., Thomson, A. M., VanVuuren, D., Weyant, J., and Wilbanks, T.: Representative Concentration Pathways: A New Approach to Scenario Development for the IPCC Fifth Assessment Report, Nature, 463 747-756, 2010.

Murphy, D. M., Solomon, S., Portmann, R. W., Rosenlof, K. H., Forster, P. M., and Wong, T.: An observationally based energy balance for the Earth since 1950, J. Geophys. Res., 114, D17107, doi:10.1029/2009JD012105, 2009.

Myhre, G., Berglen, T. F., Johnsrud, M., Hoyle, C. R., Berntsen, T. K., Christopher, S. A., Fahey, D. W., Isaksen, I. S. A., Jones, T. A., Kahn, R. A., Loeb, N., Quinn, P., Remer, L., Schwarz, J. P., and Yttri, K. E.: Modelled radiative forcing of the direct aerosol effect with multi-observation evaluation, Atmos. Chem. Phys., 9, 1365-1392, doi:10.5194/acp-9-1365-2009, 2009.

Penner, J. E., Li, X., and Wang, M.: Satellite methods underestimate indirect climate forcing by aerosols, P. Natl. Acad. Sci. USA, 108, 13404-13408, 2011.

Quaas, J., Boucher, O., Bellouin, N., and Kinne, S.: Satellite-based estimate of the direct and indirect aerosol climate forcing, J. Geophys. Res., 113, 129-234, doi:10.1029/2007JD008962, 2008.

Riahi, K., Rao, S., Krey, V., Cho, C., Chirkov, V., Fischer, G., Kindermann, G., Nakicenovic, N., and Rafaj, P.: RCP 8.5 - A scenario of comparatively high greenhouse gas emissions, Clim. Change, 109, 33-57, 2011.

Santer, B. D., Taylor, K. E., Wigley, T. M. L., Penner, J. E., Jones, P. D., and Cubasch, U.: Towards the detection and attribution of an anthropogenic effect on climate, Clim. Dynam., 12, 77-100, 1995.

Schultz, M. G., Heil, A., Hoelzemann, J. J., Spessa, A., Thonicke, K., Goldammer, J., Held, A. C., Pereira, J. M., and van het Bolscher, M.: Global Wildland Fire Emissions from 1960 to 2000, Global Biogeochem. Cy., 22, GB2002, doi:10.1029/2007GB003031, 2008.

Schulz, M., Textor, C., Kinne, S., Balkanski, Y., Bauer, S., Berntsen, T., Berglen, T., Boucher, O., Dentener, F., Guibert, S., Isaksen, I. S. A., Iversen, T., Koch, D., Kirkevåg, A., Liu, X., Montanaro, V., Myhre, G., Penner, J. E., Pitari, G., Reddy, S., Seland, $\varnothing .$, Stier, P., and Takemura, T.: Radiative forcing by aerosols as derived from the AeroCom present-day and pre-industrial simulations, Atmos. Chem. Phys., 6, 5225-5246, doi:10.5194/acp-65225-2006, 2006.

Shindell, D. and Faluvegi, G.: Climate response to regional radiative forcing during the twentieth century, Nat. Geosci., 2, 294-300, 2009.

Skeie, R. B., Berntsen, T. K., Myhre, G., Tanaka, K., Kvalevåg, M. M., and Hoyle, C. R.: Anthropogenic radiative forcing time series from pre-industrial times until 2010, Atmos. Chem. Phys., 11, 11827-11857, doi:10.5194/acp-11-11827-2011, 2011.

Smith, S. J.: Income and Pollutant Emissions in the $\mathrm{O}^{\mathrm{bj}}$ ECTS MiniCAM Model, J. Environ. Devel., 14, 175-196, 2005.

Smith, S. J. and Wigley, T. M. L.: Multi-Gas Forcing Stabilization with the MiniCAM. Energy Journal (Special Issue \#3), 2006.

Smith, S. J., Pitcher, H., and Wigley, T. M. L.: Future Sulfur Dioxide Emissions, Clim. Change, 73, 267-318, 2005.

Smith, S. J., West, J. J., and Kyle, P.: Economically Consistent Long-Term Scenarios for Air Pollutant and Greenhouse Gas Emissions, Clim. Change, 108, 619-627, 2011. 
Smith, S. J., van Aardenne, J., Klimont, Z., Andres, R. J., Volke, A., and Delgado Arias, S.: Anthropogenic sulfur dioxide emissions: 1850-2005, Atmos. Chem. Phys., 11, 1101-1116, doi:10.5194/acp-11-1101-2011, 2011

Stott, P. A., Mitchell, J. F. B., Allen, M. R., Delworth, T. L., Gregory, J. M., Meehl, G. A., and Santer, B. D.: Observational Constraints on Past Attributable Warming and Predictions of Future Global Warming, J. Climate, 19, 3055-3069, doi:10.1175/JCLI3802.1, 2006.

Streets, D. G., Bond, T. C., Lee, T., and Jang, C.: On the future of carbonaceous aerosol emissions, J. Geophys. Res., 109, D24212, doi:10.1029/2004JD004902, 2004.

Streets, D. G., van Aardenne, J., Battye, B., Garivait, S., Grano, D., Guenther, A., Klimont, Z., Lamarque, J. F., Lu, Z., Maenhout, G., Ohara, T., Parrish, D. J., Smith, S. J., and Vallack, H.: Emission Inventories and Projections, in: Hemispheric Transport of Air Pollution (2010) Part A: Ozone and Particulate Matter, Chapter 3. Air Pollution Studies No. 17, edited by: Dentener, F., Keating, T., and Akimoto, H., 77-133, UNECE Information Service, Geneva, Switzerland, 2010.

Taylor, K. E. and Penner, J. E.: Response of the climate system to atmospheric aerosols and greenhouse gases, Nature, 369, 734737, 1994.

Thomson, A. M., Calvin, K. V., Smith, S. J., Kyle, G. P., Volke, A., Patel, P., Delgado-Arias, S., Bond-Lamberty, B., Wise, M. A., Clarke, L. E. and Edmonds, J. A.: RCP4.5: A Pathway for Stabilization of Radiative Forcing by 2100 , Clim. Change, 109, 77-94, doi:10.1007/s10584-011-0151-4, 2011.

van der Werf, G. R., Randerson, J. T., Giglio, L., Collatz, G. J., Kasibhatla, P. S., and Arellano Jr., A. F.: Interannual variability in global biomass burning emissions from 1997 to 2004, Atmos. Chem. Phys., 6, 3423-3441, doi:10.5194/acp-6-3423-2006, 2006. van Vuuren, D. P., Meinshausen, M., Plattner, G.-K., Joos, F., Strassmann, K. M., Smith, S. J., Wigley, T. M. L., Raper, S. C. B., Riahi, K., de la Chesnaye, F., den Elzen, M., Fujino, J., Jiang, K., Nakicenovic, N., Paltsev, S., and Reilly, J. M.: Temperature increase of 21 st century mitigation scenarios, P. Natl. Acad. Sci. USA, 105, 15258-15262, 2008.

van Vuuren, D. P., Stehfest, E., den Elzen, M. G. J., Kram, T., van Vliet, J., Deetman, S., Isaac, M., Goldewijk, K. K., Hof, A., Beltran, A. M., Oostenrijk, R., and van Ruijven, B.: RCP2.6: exploring the possibility to keep global mean temperature increase below $2{ }^{\circ} \mathrm{C}$, Clim. Change, 109, 95-116, 2011.

Wang, M., Ghan, S., Ovchinnikov, M., Liu, X., Easter, R., Kassianov, E., Qian, Y., and Morrison, H.: Aerosol indirect effects in a multi-scale aerosol-climate model PNNL-MMF, Atmos. Chem. Phys., 11, 5431-5455, doi:10.5194/acp-11-5431-2011, 2011.

Wigley, T. M. L.: Possible climate change due to $\mathrm{SO}_{2}$-derived cloud condensation nuclei, Nature, 339, 365-367, 1989.

Wise, M. A., Calvin, K. V., Thomson, A. M., Clarke, L. E., BondLamberty, B., Sands, R. D., Smith, S. J., Janetos, T. C., and Edmonds, J. A.: Implications of Limiting $\mathrm{CO}_{2}$ Concentrations on Land Use and Energy, Science, 324, 1183-1186, 2009.

Yan, F., Winijkul, E., Jung, S., Bond, T. C., and Streets, D. G. Global emission projections of particulate matter (PM): I. Exhaust emissions from on-road vehicles, Atmos. Environ., 45, 4830-4844, doi:10.1016/j.atmosenv.2011.06.018, 2011. 